\title{
Healthcare clinic and pharmacy chains in Kenya and Nigeria: How are they regulated, and what opportunities and risks do they present to national regulatory systems?
}

Francis Wafula ( $\sim$ fwafula@strathmore.edu )

Strathmore University

Chima Onoka

University of Nigeria, Enugu Campus

Anita Musiega

Strathmore University

Arnold Okpani

National Primary Health Care Development Agency

Dosila Ogira

Strathmore University

Ufuoma Ejughemre

Delta State Contributory Health Commission, Asaba, Delta State

Rosalind Miller

London School of Hygiene \& Tropical Medicine

Catherine Goodman

London School of Hygiene \& Tropical Medicine

Kara Hanson

London School of Hygiene \& Tropical Medicine

\section{Research Article}

Keywords: Regulation, Retail pharmacies, Consolidation, pharmacy chains

Posted Date: December 21st, 2020

DOI: https://doi.org/10.21203/rs.3.rs-129236/v1

License: (c) (1) This work is licensed under a Creative Commons Attribution 4.0 International License.

Read Full License 


\section{Abstract}

Introduction Regulating highly fragmented healthcare markets is a major challenge in low- and middleincome countries, with compliance often very poor. We investigated market consolidation through the emergence of clinic and pharmacy chains in Kenya and Nigeria and explored the regulatory opportunities and risks that chains present.

Methods The study was conducted in Nairobi, Kenya and the Federal Capital Territory, Nigeria, with chains defined as businesses with four or more establishments. Data were collected through document reviews and 26 interviews with chain operators, professional associations and regulators between September and December 2018. A thematic analysis was conducted.

Results While chain clinics and pharmacies still accounted for a relatively small share of these markets, their importance was growing. We identified both organic-growth chains which had started as single business locations and gradually expanded, and investor-driven chains that used external investment capital to rapidly buy out businesses or establish new ones. In both countries, chains were regulated in an identical manner to independents, with all branches treated as independent units. Regulators neither capitalized on opportunities presented nor guarded against potential risks. The chains' brand visibility and centralized management systems were seen as having the potential to encourage self-regulation, and improve regulatory efficiency, but regulators were not exploiting this. Potential risks identified were chains gaining excessive market power, and encouraging greater commercialization of professional healthcare, putting public health at risk. Chains tended to have regular interaction with regulators, which some feared could lead to excessive influence over the regulatory process.

Conclusion As the market shares of clinic and pharmacy chains continues to rise, regulatory bodies should modify regulatory requirements and process to take advantage of chains' brand visibility and centralized management and quality assurance systems, as well as guarding against the risks of monopolization, commercialization and regulatory capture.

\section{Background}

Healthcare markets in most low- and middle-income countries (LMICs) are characterized by large numbers of individually-owned establishments (1) (2). This market fragmentation is particularly notable for retail pharmacies and smaller clinics, two provider types that provide a large share of private sector healthcare, including for poorer communities (3-5). Pharmacies and small clinics provide quick and convenient access to medical advice and products, and are often relatively affordable $(6,7)$. However, highly fragmented markets have been associated with poor performance in public health terms, linked to high levels of competition, inadequately qualified staff, and limited regulatory oversight (8). Unlawful practices are widespread, including practicing outside one's scope, violating staffing and equipment/infrastructure requirements, operating without a valid license, stocking unauthorized products, and lack of adherence to prescription restrictions (7) (9) (5). 
There is increasing interest in whether measures to support market consolidation can address some of these performance issues $(7,9)$. In healthcare markets, consolidation has mainly taken the form of chains, defined as a single parent company owning multiple business locations. Chains are currently much more common in high-income countries. In the UK, for instance, roughly half of the retail pharmacy market is controlled by 12 chain operators (10). Though less common in LMICs, chains have gained traction in some settings such as Latin America, South Africa and India (11-13). For example, according to information from respective company websites, the Mexican pharmacy chain Farmacias Similares expanded from one shop in 1997 to more than 6,400 in 2020, while in India, chains command an increasing share of the hospital market including such famous names as Apollo, Fortis and Narayana.

Although experiences from non-healthcare markets have shown chains to improve quality and lower prices $(14,15)$, evidence on their impact in LMIC healthcare markets remains scant. Chains are argued to have advantages for both the provider and the patient; they may expand the range of services and commodities available, exploit economies of scale to lower prices, improve operational efficiency, promote business brand visibility, and increase the sustainability of healthcare businesses $(11,18)$. In addition, internal controls within chains could improve regulatory compliance. However, chains with substantial market power could also pose risks, in terms of monopolization and excessive influence on regulators.

We sought to study the expanding clinic and pharmacy chains in Kenya and Nigeria. These, countries have two of the most developed private healthcare sectors in sub-Saharan Africa, with a proliferation of small clinics, retail pharmacies, and in Nigeria, smaller medicine retailers known as patent medicine vendors $(5,19)$. We aimed to understand the regulatory response to chain development in both countries and to identify the opportunities and risks that chains present for public health.

\section{Methods}

The study was carried out in Kenya's capital, Nairobi, and the Federal Capital Territory (FCT) in Nigeria, which contains Nigeria's capital, Abuja. These are both large metropolitan areas with high concentration of chains and are home to the relevant regulatory agencies.

There is no standard definition of a chain. Studies have defined chains to include businesses with more than one establishment (20), four or more establishments (21) and more than ten establishments (22). We used the definition of four or more establishments, recognizing that it was common for businesses to have a branch or two but not exhibit chain characteristics, while reflecting that chains were relatively new in both countries and likely to have fewer outlets than those in high-income settings.

Data were collected through a detailed document review, and qualitative interviews. The document review entailed searches for relevant legislation, policy documents and regulatory tools and guidelines. Document sources included websites of the respective regulatory bodies, professional associations and ministries of health. Hard copy documents were also obtained from the offices of the regulatory agencies. 
These were complemented by snowball searches seeking to identify articles referred to in the policy and regulatory documents (supplementary file 1)

The document review informed the identification of a list of potential interviewees, as well as the development of interview topic guides tailored to each interviewee type (supplementary file 2). Using the topic guide, in-depth interviews were conducted with 26 actors (14 in Kenya and 12 in Nigeria). For Kenya, interviewees included nine clinic or pharmacy chain operators, all with headquarters in Nairobi; and five regulatory and professional association managers. For Nigeria, interviewees included six chain operators and six regulatory and professional association managers. The interviews were carried out between September and December 2018.

Interview questions were structured around three broad themes: the nature, characteristics and practice of clinic and pharmacy chains; the regulatory agency response (if any); and the emerging regulatory opportunities and risks. An information sheet was provided for each interview, and individual consent sought. Where consent was granted, interviews were tape-recorded, and notes were taken during all interviews. Interviews were transcribed, with transcripts entered into NVIVO 12 for content management. A thematic analysis approach was taken, drawing on a pre-defined coding structure informed by the interview topic guide, with a focus on the three broad themes outlined above. Ethics clearance was provided by the Strathmore University Ethics Review Committee, the Federal Capital Territory Health Research Ethics Committee, Nigeria, and the Ethics Committee of the London School of Hygiene and Tropical Medicine.

\section{Findings}

We begin by describing clinic and pharmacy chain businesses in the two countries, and their regulation, before turning to the risks and opportunities they present for regulation and public health.

\section{Development of pharmacy and clinic chains}

We classified chains into two broad categories based on origin and growth: organic-growth chains and investor-driven chains. Organic-growth chains started off as single business locations and expanded slowly to multiple sites over time, without major changes in ownership or branding. On the other hand, investor-driven chains emerged from external injection of investment capital. They typically entered the market by buying out many established businesses and giving them a corporate brand identity. They then typically expanded further through acquisition and establishment of businesses in new sites.

Although a growing trend, chains still controlled a relatively small share of the clinic and pharmacy markets in both countries, mainly concentrated in the largest cities. In Kenya, since 2012 two investordriven retail pharmacy chains have emerged, Goodlife and Haltons, with 41 and 17 branches respectively at the time of the study. Haltons had adopted a greenfield expansion strategy, setting up pharmacies in newly developed real estate, initially expanding to over 100 sites before shrinking back to the current footprint. Goodlife, on the other hand, entered the market through buying out existing pharmacies. 
Examples of organic-growth chains included Dovey and Malibu Pharmacy, which had expanded to 5 and 7 branches respectively in a range of strategic locations. At the time of the study the largest pharmacy chain had 41 stores, still a small number compared to the country's overall estimated total of 15,000 pharmacies (of which around 5,000 are licenced). The market share of pharmacy chains also remained low - estimated by one manager to be below $3 \%$ of licenced pharmacy sales. The three largest Kenyan commercial clinic chains had 10-20 establishments each, also a very small fraction of the over 5,100 private health facilities. One clinic chain had initially been established as a non-profit franchise but was transitioning to commercial business status for sustainability.

In Nigeria's FCT, the oldest chains could be traced back to the early 2000s. However, these only expanded beyond single digits in the decade preceding the study. At the time of the interviews (late 2018), there were 10 clinic chains operating in the FCT area, constituting just under $5 \%$ of nearly 700 registered private clinics. At least two of the clinic chains also had operations in other Nigerian states. Pharmacy chains have similarly grown over the same period, but like clinic chains, still constituted a relatively small proportion of all pharmacies. The largest chain - HealthPlus Pharmacy - had about 50 stores throughout Nigeria, of which four were in the FCT. Chain pharmacies tended to be concentrated in the more affluent areas. Only 30 of the 442 pharmacies in the Abuja Municipal Area Council (which forms part of the FCT) were part of a chain, yet they were said to be responsible for $30-40 \%$ of all sales in that area.

The growth of clinic and pharmacy chains in the FCT, Nigeria, was considered largely organic, except for HealthPlus which had received foreign private equity investment.

In both countries, chains were said to predominately serve middle- or high-income groups within the population. Some chains in Kenya had entered into strategic partnerships to enhance their range of services, or increase convenience for customers. Goodlife, a Kenyan chain entered into a formal partnership with a major laboratory chain to offer diagnostic services with sample collection in pharmacy stores, while Haltons, another Kenyan firm had partnered with an oil marketer to set up stores at its petrol stations. Malibu chain partnered with a private health insurance company.

...last year is when we began aggressive expansion and we want to focus in towns outside Nairobi since there are no pharmacies that do insurance. The insurance companies wanted to extend that partnership outside Nairobi........ we are opening more shops due to demand especially from the insurance companies.' Kenya pharmacy operator 3

Nigerian regulation was generally more restrictive on such partnership arrangements.

\section{Regulation of chains}

In Kenya, pharmacies are regulated by the Pharmacy and Poisons Board (PPB), and clinics by the Kenya Medical Practitioners and Dentists Council (KMPDC), while in Nigeria the respective bodies are the Pharmacists Council of Nigeria (PCN) and, for clinics in the FTC, the Private Health Establishment 
Registration and Monitoring Committee (PHERMC). The Nigerian National Agency for Food and Drug Administration and Control (NAFDAC) also conducts routine inspection visits to pharmacies to check the sale of substandard or unregistered products, and the National Drug Law Enforcement Agency (NDLEA), an armed unit, conducts raids on pharmacy premises when there is a suspicion that the business is involved in illicit trade in controlled substances such as narcotics.

In both Kenya and Nigeria chains were regulated in a similar manner to independents, with the laws requiring that all business units be licensed independently, and inspection activities making no distinction between chains and independents. In both countries regulatory inspections were carried as a prerequisite for licensing facilities, and regulators had the power to carry out impromptu inspections at any point after that. Professional staff such as pharmacists, doctors and nurses were also required to be registered by the relevant regulator. In Nigeria there was a mandatory minimum radius of $200 \mathrm{~m}$ between pharmacies and $400 \mathrm{~m}$ between clinics to minimize competition. This law did not exist in Kenya at the time of the study, although the regulator confirmed plans to introduce the rule. There were no price regulations in either country.

There was a notable difference between the two countries in ownership rules, which had important implications for chains. In Kenya, those without medical or pharmacy qualifications could own clinics or pharmacies, provided they employed qualified and licensed personnel. In Nigeria, pharmacy ownership was restricted to pharmacists, meaning those wishing to establish chains had to partner with a local pharmacist. This made investor-driven chains harder to establish in Nigeria. The restriction did not extend to Nigerian clinics, though they were required to have a Nigerian medical person in charge.

\section{Opportunities and risks arising from the emergence of chains}

We identified a number of opportunities and risks that arise from the interaction between chain businesses and the regulatory processes.

\section{Ease and efficiency of regulation}

The primary opportunity highlighted was that chains should be easier and less costly to regulate than independents. At the most basic level, chain operators argued that the corporate branding of chains made them more visible to regulators meaning that, unlike independent operators, they did not have the option of running away whenever inspectors came visiting. "Cat and mouse games" between regulators and independent pharmacies were known to be common, with the latter closing down their shop when they heard that inspections were planned. Such avoidance tactics would not be possible for more visible chain businesses.

'...the independent (stores).... if they are doing something gross (unlawful), you come for inspections and they run away. If you (inspector) come the following day you find that what was a pharmacy yesterday is a hardware today and you don't know the owner.' Nigeria pharmacy operator 3 
The increased likelihood of being selected for inspection, and the reduced chance of evading this, was said to make chains work harder towards compliance. A few chain operators even complained that this brand visibility resulted in their being "overregulated", creating an unequal playing field, with less visible, independent providers less likely to be inspected even though they were more likely to be unlicensed or to infringe other regulations.

A second reason why regulation of chains should be easier, and less necessary, than for independents was that chains had strong centralized management structures, supported by internal information management and quality assurance systems, which amounted to a form of self-regulation. As one clinic chain operator noted:

"..quality assurance, quality validation and metrics, we drive internally as part of our own strategy in a way that the regulatory bodies may not even have the capacity at the moment, for example we audit our own staff and have their performance charts and we take protocols for conditions that we treat and services that we provide and present the metrics to the team. We have external validation to our labs..."

\section{Kenya clinic operator 1}

The existence of these systems was also argued to lessen the regulators' workload. It was easy for chains to generate internal reports, which could be sent to the regulator regularly, who could then just visit the chain headquarters or audit the reports, without needing to visit all branches.

"It is actually easier (to regulate chains) because for instance we have $X$ (number) stores and instead of going to each of the individual shops it is easy to come to head office who will disseminate the information as opposed to dealing with all of them. With chains it is also easier to implement the rules because there is an internal corporate structure that ensures you are following regulations." Kenya pharmacy operator 2

Some chain businesses processed and paid for licenses for all their staff in bulk across the chain, meaning that regulators received license fees in good time. One chain operator argued that also made it easier for regulators to link licensed persons to specific establishments, something that regulators struggled with in Kenya.

Investor-driven chains were said to undertake due diligence before buying existing establishments to ensure they acquired legitimate businesses. Some of those interviewed felt that this gave regulators the opportunity to engage with chain operators early in the process, guiding them towards selecting acceptable business practices.

"(It is easier to regulate chains) because they all fall under a system that is standardized and as they grow and achieve geometric scaling, you are assured that the standard is met." Kenya clinic operator 4

Some regulators agreed that it was easier to inspect chain establishments due to their having auditable systems in place. 
"They (chains) have a central command system where they have their protocols on patient safety and patient care. In fact, they assist us in ensuring that there is conformity with the regulations." Kenya clinic regulator

"... our name and brand makes it easier for them (regulators) to come around, and we help them too because we give them the good environment and make the things easier for them to check and regulate. We give them the standard that they can use to even to regulate other people." Nigeria pharmacy chain operator 6

However, there was no evidence that regulators were currently exploiting the potential to improve regulatory efficiency by more centralized regulation and inspection of chains, rather continuing to treat all business sites individually. Infractions in one branch did not automatically trigger interest in other branches of the same chain. Some chain operators expressed disappointment with this:

"I don't think they've thought about the fact that if it's a chain... what you find in one (establishment) is possibly available in the other branches and should be looked into." Nigerian clinic operator 4

This could be a missed opportunity, especially given the challenges regulators in both countries faced in conducting regular inspections of each provider.

"I think the current major challenge is that there are lots of pharmacies out there than they used to be. You find out that sometimes you don't have any of these regulatory bodies walk into the pharmacy for routine inspections for a whole year. It's as if they [regulators] are kind of overwhelmed by the number of pharmacies out there. They don't have enough [people] to go round" Nigeria pharmacy operator 1

They also felt that procedures for opening new stores could be made simpler for chains that had demonstrated good compliance in the past, but this was not currently the case. However, not all chain operators liked the idea of having a different system for regulating chains. In Kenya while investor-led chains supported this, organic-growth chains preferred the system where stores were treated independently, one arguing that such systems ensured that impropriety in one establishment did not punish other establishments owned by the chain.

"Another advantage is that outlets are penalized individually even if they are owned by chains and this does not affect other outlets, hence there is management of risk." Kenya pharmacy operator 4

\section{Beneficial cooperation or regulatory capture?}

Several chain operators stressed that they wanted to cooperate with regulators in enhancing the performance of the whole sector, with one saying they had a duty to support regulators to bring order. These repeated interactions were said to have improved relations with regulators, and even supported the latter in developing standards. 
"... we were the first to be inspected in Nairobi County. We have worked with Nairobi County team on iteration of how our model looks like, the kind of services we offer, square footage of the clinic, and with every new facility, it's faster since it is a standard that we have agreed on and integrated with what Nairobi County has on paper." Kenya clinic operator 1

"... we wanted to do a study with PPB to see what are the factors that drive illegal pharmacy practices and what should be done to mitigate the risks..." Kenya pharmacy operator 2

Chain operators argued that their good relations with regulators were a means to improve compliance and practice through cooperation, and that it was in their interest to have a properly functioning regulatory system, to minimize competition with non-compliers. However, this frequent interaction worried some interviewees, who saw a risk of regulatory capture, where regulators become dominated by the interests of chains, rather than the broader public good. This was perceived to be compounded by the fact that that chains were better resourced than independents, with big chains able to sponsor events and make large donations to regulatory agencies.

"...these chain pharmacies are more powerful when it comes to regulation...because they have money to throw around and can actually control or influence the way regulators work. It is not as if the regulatory bodies can enforce the rules properly when it comes to chains. They can bend rules for some of them depending on who knows who..." Nigeria pharmacy operator 2

However, one chain operator disagreed with this idea, stressing that such interactions were helpful to regulators.

\section{Commercialisation}

A second risk associated with the emergence of chains was that it could lead to greater commercialization of the clinic and pharmacy sectors, as more non-professionals became interested and involved in healthcare businesses. As noted above, in Nigeria all pharmacies had to have a pharmacist as owner, but clinics in Nigeria and both pharmacies and clinics in Kenya could be owned by nonprofessionals as long as they employed licensed personnel for each branch. However, interviewees described frequent flouting of these ownership and practice regulations. One common infringement in both countries was businesspeople using qualified personnel's certificates to register businesses, then reverting to cheaper, less-qualified staff to run the facility. This was referred to as 'fronting' in Nigeria and 'license leasing' in Kenya. While this appeared to be a market-wide problem, occurring in both chains and independents, one chain store operator linked the problem to increased entry of investor-driven chains, which they felt had contributed to commercialization of professional practice.

"...pharmacies should be owned by a pharmacist and at every point there must be a pharmacist [present]. But what we're seeing now, [in pharmacies] calling themselves chains, non-pharmacists are in the business. We call it 'fronting' here, where a pharmacist will claim to be the owner of all the businesses, meanwhile, he or she is not actually the owner." Nigeria pharmacy operator 2 
A Kenyan Pharmacy Association manager agreed that chains often failed to staff each branch with appropriately qualified staff, also arguing that where the professionals were employed, they had less influence on chain operation than the non-professionals.

"...(chain) governance can become so centralized that if there is a regulatory requirement for a pharmacist, then the chain demonstrates they have one, forgetting that they (pharmacists) are needed in every branch to interact with the patients... they (chains) reduce the number of professionals that they employ because they can get away with it. Because they have investors from private equity firms, the actual professionals don't have a big say in the operations of the chains..." Kenya Pharmacy Association Manager

\section{Monopolization}

A final risk identified was that the financial resources and rapid expansion of chains could lead to them dominating the market and wielding excessive market power. Despite their currently low numbers, chain pharmacy businesses in particular were already perceived to be affecting sales of independents, reflecting their greater efficiency and wholesale purchasing power. Concern about this was mainly expressed by the Pharmacy Association interviewees.

"If a chain pharmacy moves to a location, in time, we discover that smaller pharmacies or stand-alone pharmacies start complaining that the chain pharmacies have taken over the market. Their clients have changed base..." Nigeria Pharmacy Association Manager

Investor-led chains were particularly seen as a monopoly risk, with fears that their expanding footprint and sales volumes could edge out independent competitors, enabling the chains to manipulate prices in the future. It was also argued that the intense competition could encourage independents to engage in illegal practices just to maintain some market share.

"... Their (chain pharmacies) sheer presence and financial muscle tend to be a little bit intimidating for the regulators..." Kenya Pharmacy Association Manager

"There should be a maximum number of pharmacies that can be acquired or owned so that other people can have a say in the business. To us, we're not happy with the way they (chain stores) are springing up, spreading everywhere and not giving anyone else the chance. You can imagine (the chain) sees a place, not minding other pharmacies, immediately they go into that place, other businesses close. It is worrisome. The regulatory bodies need to come into this matter, else, it forces others to do all kinds of things to survive." Nigeria Pharmacy Association Manager

The same Pharmacy Association manager highlighted one particular practice of investor-driven chains which involved offering to pay incumbent independents to relocate.

"Now it is all those chain businesses that are our problem; they'll even come and tell you, 'I don't mind relocating you', 'I don't mind relocating your shop for you'. Yes, because they have the money, they have 
the resources, so they say, 'I want to be here, so if you feel that you can compete with me, stay'. But they'll advise you that the best thing for you is to go far away, you know, those remote places. And they'll give you money to just give them chance to stay." Nigeria Pharmacy Association Manager

However, the health regulators did not express concern about the rising market share of chains, rather arguing that the expansion allowed economies of scale, making services and products cheaper to the consumers which was beneficial.

"Because of volumes, they [chains] have the comparative advantage of getting purchasing price lower. The smaller pharmacies are beginning to complain to us that these ones are undercutting them...it's something beyond our scope as regulators to say, "Hey! Why are you selling at this price"? If you look at it from our perspective, you know, free market and other things, you can't really call anybody to order."

\section{Nigeria pharmacy regulator 1}

Risks from excessive market power would indeed be considered outside the remit of heath regulators, rather falling to competition regulators: The Competition Authority of Kenya and the Federal Competition and Consumer Protection Commission (FCCPC) for Nigeria. However, to date neither agency had raised any objections. One chain operator observed that the Competition Authority had requested some information about their proposed expansion but had not contested it.

"We have a few takeovers in Nairobi so CAK (the competition regulator) was concerned with our monopolization... we had to get clearance." Kenya pharmacy Operator 1

\section{Discussion}

Africa's healthcare markets are undergoing considerable disruption with private sector expansion, emergence of new organizational forms and business models, and growing foreign investment. However, the regulatory systems in these countries are inadequate and ill-suited to manage these challenges and future market evolution. The emergence of chain healthcare businesses is one feature of these changes; while the market share of chains is still relatively low, there are indications that this will increase rapidly in future, supported by injections of external capital, and following similar trends in higher income countries (22). Since 2018 when the data for this paper were collected, the Kenyan pharmacy regulator has become stricter in enforcing pharmacy zoning, where new premises are denied registration if they are deemed to be located close to an existing one (distance definition determined by area population size and other factors). There have been no substantive regulatory changes in Nigeria since 2012. However, there has been some effort to relax restrictions on operation of online pharmacies. As the chain concept gains traction, regulators need to be ready to address the new challenges they present, but also to take advantage of the opportunities they provide for enhancing regulatory effectiveness and efficiency. We sought to identify these risks and opportunities through discussion with key stakeholders in Kenya and Nigeria. 
The study had a number of limitations. We interviewed a wide range of staff from chain clinic and pharmacy operators, regulators, and professional associations. There is a risk that social desirability bias will lead chain operators to paint an unrealistically favorable view of their operations and motivations. We did not interview staff from independent clinics and pharmacies, who may well have been more critical of chains, though to some degree these views were represented by professional association representatives. A further challenge in assessing the market is the lack of available quantitative data on market shares, prices and quality of service for both chains and independents. Finally, we defined chains as having four or more branches; as a result, we may have failed to include some emerging smaller chains. However, we feel that we captured the majority of businesses that exhibit key chain features such as centralized management systems and brand visibility.

The greater capitalization of chains, often based on external investment, together with the economies of scale arising from their centralized operational structure and purchasing power, was said to give them a strong competitive advantage. This was in many ways seen as beneficial for public health by interviewees, with the potential to lead to higher quality and more affordable chain services, which might also force independents to improve performance in order to compete. In non-health markets, chains have been argued to contribute to market wide improvement of services $(14,15)$, but there was a lack of evidence to support this as yet in Kenya or Nigeria's healthcare markets. The evidence from other LMICs on this issue is limited to a few pharmacy-related studies. In Thailand, chain pharmacies reported better quality performance compared to independents across various domains, including personnel, drug management and patient satisfaction (23). In China, it has been reported that chain pharmacies employ a more rigorous recruitment and training processes compared to independents (17). In Bengaluru, India, adherence to treatment guidelines was equally poor in chain and independent pharmacies, with the chains' internal quality control mechanisms focusing more on aspects linked to customer care rather than those that link directly to health outcomes $(20,24)$. However, the study found that chains were less likely to sell prescription-only medicines for diarrhea without a prescription (24). By contrast, in Mexico, pharmacy type was not associated with the sale of over-the-counter abortifacients $(25,26)$. In terms of price, one Indian study found that chain prices were somewhat lower than independents, although chains served wealthier clients compared to independent pharmacies $(16,27)$. Further, it has also been shown, in India, that the entry of chains into pharmacy retail markets can lead to increased drug quality and reduced prices in existing independent retailers (16).

Three key risks were identified by stakeholders, concerning excessive market power, commercialization and regulatory capture. There were concerns that chains were leading to an intensely competitive environment for incumbent independents, which was already driving some out of business. If investordriven chains became highly dominant this could pose access risks if they were susceptible to sudden folding or sell-out. Such instability has been reported in non-healthcare markets ${ }^{25}$. Intense competition from chains could also encourage other providers to flout regulations to gain a competitive advantage, in "race to the bottom" competition, where quality is compromised. Excessive retail-level competition has been linked to reduced regulatory compliance in Kenya (28). While there was no evidence of market 
dominance by chains as yet in either country, this may be a future risk, especially in prime business locations where chains are currently concentrated. Currently competition and practice were regulated separately in the study countries, with little liaison between the regulatory bodies. Going forward this should be enhanced with greater coordination and information sharing across regulators.

There were also fears that chains were increasing the commercialization of professional healthcare businesses, and that this would lead to greater priority being given to the profit motive over clinical quality of care and the public good. The overall impact of this was unclear. While some argued that chains were more likely to engage in "fronting" using under-qualified personnel, this practice was also known to be common in independents. It could also be argued that independents might have a more professional and patient-focused approach focus in general; in the US, a study found that patients were more satisfied with care given at independent pharmacies compared to chain pharmacies (29). However, as noted above, it could also be argued that chains' superior management systems, and centralized procurement could lead to better quality.

The key opportunity identified from the emergence of chains was in improving the ease of regulation and reducing its cost. Both clinic and pharmacy markets are currently highly fragmented, and this poses huge regulatory challenges in most LMICs, with insufficient oversight and inspections, very low levels of enforcement and resulting concerns for patient safety, quality of care and antimicrobial resistance $(24,30-34)$. Consolidation offers opportunities for regulators to engage the private providers in a structured way. First it raises the stakes for providers, creating strong disincentives for engaging in unlawful or unethical practices, as one errant branch has the potential to damage the reputation of the entire chain. Secondly the chains' own management systems could facilitate a more efficient style of regulation and inspection, based primarily on centralized electronic data and quality governance mechanisms, with much more limited monitoring of individual branches. By exploiting this, regulators could encourage and support self-driven compliance, focusing on verifying performance and advising chains on areas for improvement. This fits well with modern thinking on regulation, which places increased emphasis on cooperation between the regulator and regulatee (35), including responsive regulation methods which involve a hierarchy of measures which begins with persuasion and only gradually escalates to warnings, with more costly sanctions a last resort (36). However, appropriate accountability systems need to be in place to avoid excessive influence of chains on the regulatory process through some kind of regulatory capture.

To date this opportunity had not been exploited in Kenya or Nigeria; as chains grow there is a strong argument to review regulatory requirements and procedures to capitalize on these opportunities. However, given the current concentration of chains in relatively affluent areas, regulators will still need to develop more efficient methods for regulating independents in poorer areas, where the risks to patient safety might be expected to be highest. It should also be noted that chains are not the only way to reduce fragmentation in healthcare markets. Other forms of consolidation and coordination include the use of social franchises which were common for both pharmacies and clinics in both countries $(37,38)$, and business networks, such as the Kenya Pharmaceutical Association's Pharmnet network of independent 
pharmacies operated by pharmaceutical technologists (39). Unlike the commercial chains, Pharmnet targets lower income groups, and aims to consolidate certain aspects of their operation including pooled purchasing and quality assurance mechanisms. However, these voluntary approaches tend to face challenges in reconciling professional autonomy with central control.

\section{Conclusion}

Pharmacy and clinic chains are gradually gaining traction across Kenya and Nigeria, and likely to expand substantially in future, presenting both opportunity and risk for regulators and public health. Healthcare regulators should liaise with competition regulators to consider the potential risks of excessive market power, consider adapting regulatory requirements to counter greater commercialization, and establish accountability mechanisms that guard against regulatory capture. Most importantly they should consider the opportunities that chains provide for more efficient regulation, drawing on chains' own centralized management and quality control systems.

\section{Declarations}

\section{Ethics approval and consent to participate}

Ethical approvals were obtained from the Strathmore University Ethics Review Committee (SUIERC0258/18), the Federal Capital Territory Health Research Ethics Committee of Nigeria (FHREC/2018/01/83/13-07-18) and the Ethics Committee of the London School of Hygiene and Tropical Medicine (15792). We confirm that all methods were performed in accordance with the guidelines and regulations of the respective ethics committees. Informed consent was obtained from all participants in the study.

\section{Consent for publication}

Not applicable.

\section{Availability of data and materials}

The data generated and/or analysed during the current study are not publicly available due participant confidentiality reasons. Names of organizations/respondents were either mentioned during interviews or could be identified even when not mentioned openly. Some (appropriately redacted) interview transcripts may be available from the corresponding author on reasonable request.

\section{Competing interests}

The authors declare that they have no competing interests.

\section{Funding}


The study was funded by the Wellcome Trust (grant 210291/Z/18/Z).

\section{Authors' contributions}

F.W. contributed to the conceptualization of the study, and wrote the introduction, methods, results and discussion sections of the manuscript. A.M and D.O contributed to the implementation of the Kenyan study, as well as the analysis and interpretation of findings, and writing up. C.O., A.O. and U.E. conducted the Nigerian study, contributed to the analysis and interpretation of findings, and writing up. R.M., C.G. and K.H. significantly contributed to the conceptualization and design of the study, the interpretation of the findings, and drafting of the manuscript. All authors approved the final manuscript.

\section{Acknowledgements.}

The study was funded by the Wellcome Trust (grant 210291/Z/18/Z). The funder played no role in the design of the study, data collection, data management, data analysis and interpretation, preparation, review, and approval of the manuscript.

\section{References}

1. Ward K, Sanders D, Leng H, Pollock AM. Assessing equity in the geographical distribution of community pharmacies in South Africa in preparation for a national health insurance scheme. Bull World Health Organ. 2014 Jul;92(7):482-9.

2. Sabde YD, Diwan V, Saraf VS, Mahadik VK, Diwan VK, De Costa A. Mapping private pharmacies and their characteristics in Ujjain district, Central India. BMC Health Serv Res. 2011 Dec;11(1):351.

3. Goodman C, Brieger W, Unwin A, Mills A, Meek S, Greer G. Medicine sellers and malaria treatment in sub-Saharan Africa: what do they do and how can their practice be improved? Am J Trop Med Hyg. 2007 Dec;77(6 Suppl):203-18.

4. Liu J, Prach LM, Treleaven E, Hansen M, Anyanti J, Jagha T, et al. The role of drug vendors in improving basic health-care services in Nigeria. Bull World Health Organ. 2016 Apr;94(4):267-75.

5. World Bank Group. The Business of Health in Africa: Partnering with the Private Sector to Improve People's Lives. The Business of Health in Africa. 2011.

6. Treleaven E, Liu J, Prach LM, Isiguzo C. Management of paediatric illnesses by patent and proprietary medicine vendors in Nigeria. Malar J. 2015 Dec;14(1):232.

7. Miller R, Goodman C. Performance of retail pharmacies in low- and middle-income Asian settings: a systematic review. Health Policy Plan. 2016 Sep;31(7):940-53.

8. Oyeyemi AS, Ogunnowo BE, Odukoya O0. Patent Medicine Vendors in Rural Areas of Lagos Nigeria: Compliance with Regulatory Guidelines and Implications for Malaria Control. Trop J Pharm Res. 2014;13(1):163-9.

9. Wafula FN, Miriti EM, Goodman CA. Examining characteristics, knowledge and regulatory practices of specialized drug shops in Sub-Saharan Africa: A systematic review of the literature. BMC Health 
Serv Res. 2012;12(1).

10. Sukkar E. Community Pharmacy in Great Britain 2016: A Fragmented Market. Pharm J. 2016;

11. Lowe RF, Montagu D. Legislation, regulation, and consolidation in the retail pharmacy sector in lowincome countries. South Med Rev. 2009;2.

12. Ayub M, Mustafa M. An Overview of Unorganized Retail Pharmacy in Indian Pharmaceutical Industry.

13. Center for Health Markets Innovation. Database at a Glance: Pharmacy Chains. 2014;

14. McGEE J, Finney B. Journal of business \&amp; entrepreneurship: JBE: a publication of the Southwestern Small Business Institute Association and the School of Business at Northwestern State University. J Bus Entrep. 1997 Mar;9(1):59.

15. McGee J, Shook C. Responding to Industry Consolidation in Fragmented Industries: The role of Capabilities in Small Business Survival. J Small Bus Strateg.

16. Bennett D, Yin W. The Market for High-Quality Medicine: Retail Chain Entry and Drug Quality in India. Rev Econ Stat MIT Press. 2019;101(1):76-90.

17. Xi X, Huang Y, Lu Q, Ung COL, Hu H. Community pharmacists' opinions and practice of pharmaceutical care at chain pharmacy and independent pharmacy in China. Int J Clin Pharm. 2019 Apr;41(2):478-87.

18. IFC. Private Healthcare Markets in Emerging Markets: An Investor's Perspective. IFC Newsletter, Int Financ Corp. 2019;(7).

19. Beyeler N, Liu J, Sieverding M. A Systematic Review of the Role of Proprietary and Patent Medicine Vendors in Healthcare Provision in Nigeria. 2015;1-21. Available from: http://dx.doi.org/10.1371/journal.pone.0117165

20. Miller R, Goodman C. Do chain pharmacies perform better than independent pharmacies? Evidence from a standardised patient study of the management of childhood diarrhoea and suspected tuberculosis in urban India. BMJ Glob Heal. 2017 Sep;2(3):e000457.

21. Schommer JC, Brown LM, Sogol EM. Work profiles identified from the 2007 pharmacist and pharmaceutical scientist career pathway profile survey. Am J Pharm Educ. 2008;72(1).

22. Olson A, Schommer J, Hadsall R. A 15 Year Ecological Comparison for the Market Dynamics of Minnesota Community Pharmacies from 2002 to 2017. Pharmacy. 2018;6(2):50.

23. Arkaravichien W, Wongpratat A, Lertsinudom S. Quality indicators to compare accredited independent pharmacies and accredited chain pharmacies in Thailand. Int J Clin Pharm. 2016 Aug;38(4):899-907.

24. Miller R, Hutchinson E, Goodman C. 'A smile is most important.' Why chains are not currently the answer to quality concerns in the Indian retail pharmacy sector. Soc Sci Med. 2018 Sep;212:9-16.

25. Lara D, García SG, Wilson KS, Paz F. How often and under which circumstances do Mexican pharmacy vendors recommend misoprostol to induce an abortion? Int Perspect Sex Reprod Health. 2011 Jun;37(2):75-83. 
26. Billings DL, Walker D, Mainero del Paso G, Clark KA, Dayananda I. Pharmacy worker practices related to use of misoprostol for abortion in one Mexican state. Contraception. 2009 Jun;79(6):445-51.

27. Miller R, Goodman C. Cheaper Medicines for the Better Off? A Comparison of Medicine Prices and Client Socioeconomic Status Between Chain and Independent Retail Pharmacies in Urban India. Int J Heal policy Manag. 2020 Nov;

28. Wafula F, Abuya T, Amin A, Goodman C. The policy-practice gap: describing discordances between regulation on paper and real-life practices among specialized drug shops in Kenya. BMC Health Serv Res. 2014 Sep;14:394.

29. Briesacher B, Corey R. Patient satisfaction with pharmaceutical services at independent and chain pharmacies. Am J Heal Pharm. 1997 Mar;54(5):531-6.

30. Morgan DJ, Okeke IN, Laxminarayan R, Perencevich EN, Weisenberg S. Non-prescription antimicrobial use worldwide: a systematic review. Lancet Infect Dis. 2011 Sep;11(9):692-701.

31. Jacobs TG, Robertson J, van den Ham HA, Iwamoto K, Bak Pedersen H, Mantel-Teeuwisse AK. Assessing the impact of law enforcement to reduce over-the-counter (OTC) sales of antibiotics in low- and middle-income countries; a systematic literature review. BMC Health Serv Res. 2019;19(1):536.

32. Bloom G, Henson S, Peters DH. Innovation in regulation of rapidly changing health markets. Global Health. 2014;10(1):1-11.

33. Sheikh K, Saligram PS, Hort K. What explains regulatory failure? Analysing the architecture of health care regulation in two Indian states. Health Policy Plan. 2015;30(1):39-55.

34. Wafula F, Molyneux C, Mackintosh M, Goodman C. Protecting the public or setting the bar too high? Understanding the causes and consequences of regulatory actions of front-line regulators and specialized drug shop operators in Kenya. Soc Sci Med. 2013;97.

35. Balleisen EJ, Eisner M. The Promise and Pitfalls of Co-Regulation: How Governments Can Draw on Private Governance for Public Purpose. New Perspect Regul. 2009;127-49.

36. Healy J, Braithwaite J. Designing safer health care through responsive regulation. Med J Aust. 2006 May;184(S10):S56-9.

37. Sundari Ravindran TK, Fonn S. Are social franchises contributing to universal access to reproductive health services in low-income countries? Reprod Health Matters [Internet]. 2011;19(38):85-101. Available from: http://www.sciencedirect.com/science/article/pii/S0968808011385813

38. Sieverding M, Briegleb C, Montagu D. User experiences with clinical social franchising: qualitative insights from providers and clients in Ghana and Kenya. 2015;1-11.

39. Kenya Pharmaceutical Association. Pharmnet [Internet]. 2020 [cited 2020 Dec 3]. Available from: https://kpanairobi.com/website/?page_id=453

\section{Supplementary Files}

This is a list of supplementary files associated with this preprint. Click to download. 
- SupplementarymaterialWafula.docx 